\title{
Research on Effective Properties of Hybrid Nano Composites
}

\author{
S. S. Godara, P. K. Mahato
}

\begin{abstract}
Carbon nano tube fiber reinforced hybrid smart composites are often used in many engineering applications due to their high specific mechanical properties. This paper is concerned with the investigation of effective elastic and piezoelectric properties of hybrid smart nano composites. For this purpose, a hybrid smart composite reinforced with carbon nanotubes (CNTs) and piezoelectric fibers is proposed. The effective properties for the proposed composite are estimated analytically by using Mori Tanaka method. The different diameters of CNTs were taken for the analysis purpose. The effect of CNT diameters on the volume fractions of piezoelectric fibers for the proposed composite is examined. The results clearly highlight the benefits of using different types of CNTs. It is found that the change in diameter can play a significant role in the determination of effective properties of CNT reinforced hybrid composites.
\end{abstract}

Keywords: Carbon nanotubes, smart composite, piezoelectric fibers, elastic constants.

\section{INTRODUCTION}

Since the inception of carbon nano tubes (CNTs), they are extensively used in research due to their extra ordinary mechanical properties [1]. Due to this, they are used as the replacement for conventional polymer composite materials and they have drawn considerable attention from researchers in many engineering applications such as structural, chemical, textile, mechanical, electrical and aerospace applications etc. [2-3]. When more than one fibers are used as reinforcements then composites are known as hybrid composites. The advantages of hybrid composite are that it could complement the fiber properties which are lacking in another type of fiber [4].

The effective elastic and piezoelectric properties for the proposed composite are investigated by using analytical mechanics based Mori Tanaka method (MTM) [5]. This MTM offers a much more economical and effective way for understanding the mechanical behavior and optimal structure design of the composite [6]. Also, the MTM is considered to be fast as well as a valid alternative for the finite element modeling analysis of composites [7]. It was reformulated for the determination of effective constants of piezoelectric composites [8].

Various models and methods were suggested to predict elastic and piezoelectric properties for the different composite models. For example, a new hybrid piezoelectric composite reinforced with zig zag single wall carbon nano tubes and piezoelectric fibers is proposed and prediction of effective properties was carried out with the help of micromechanical method [9]. Another new fuzzy fiber reinforced nano composite model was proposed and its effective properties were investigated by using a micromechanical approach [10].

The Eshelby tensor plays important role for prediction of effective constants in MTM method. It has been revealed that inclusion problem can be resolved with the help of superposition principle of linear elasticity [11]. The tensors provide the basis for the analysis of the composites and have numerous applications such as to the study of defects, overall properties of multiphase composites, and fracture mechanics, etc. The Eshelby tensor for the MTM was proposed for the piezo composites [12]. The various important attempts have been found for the calculation of Eshelby tensor for the various inclusion problems [13-15].

This work is inspired for the requirement of investigation of effective properties of hybrid nano composites. So, the main focus of this research is to calculate the effective properties of hybrid nano composites by considering a new model. For this purpose, a new model was proposed, in which CNTs and piezoelectric materials are used as reinforcing fibers and polyimide is used as a matrix material. The effective properties were determined with the help of Mori Tanaka method. It is found from the literature review that most of the researchers have assumed CNTs to be grown in the perpendicular direction while analyzing the composites. This model is proposed to understand the behavior proposed composite with fiber volume fractions. The required formulation for the MTM method is derived by considering average internal stresses.

\section{INTRODUCTION TO PROPOSED COMPOSITE\& METHODOLOGY}

The lamina of the proposed piezoelectric nano polyimide composite (PNPC) reinforced with CNTs and piezoelectric fiber is shown in Fig.1. The constructional distinctive attribute of PNPC is that the piezoelectric (PZT) materials are used as longitudinal cylindrical fibers. The nanotubes are evenly aligned along the circumferential surface of PZT in the direction of PZT. It is designed to such an extent that electric field is smeared along the length of the PZT fibers and polyimide is used as matrix. 


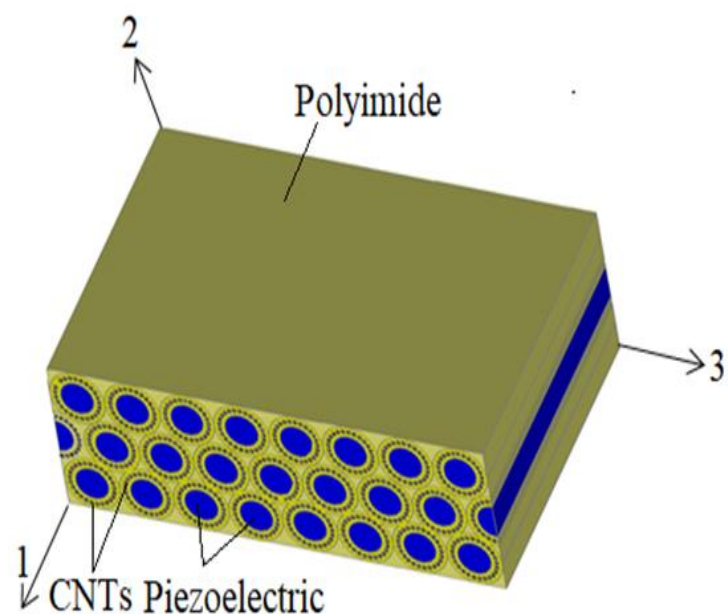

Fig.1 Sketch of the proposed PNPC

Fig.2 depicts the cross sections in transverse and longitudinal directions for the proposed PNPC, here CNTs are assumed transversely isotropic [16]. CNTs are developed on the surface of piezoelectric fibers so that their axis of transverse isotropy is normal to the surface of PZT fibers. Consequently, final composite can be observed like circular cylindrical composite, where PZT fiber is inserted in the nanotube reinforced hybrid PNPC composite. It is assumed that the proposed composite is homogeneous, the fibers are continuous and parallel.

The three step procedure is used for determination of effective properties of the proposed PNPC by MTM. First step shows the determination of effective properties of nanocomposite (NC). In the second step properties of piezoelectric nano composite (PNC) are evaluated. In the third step properties of PNPC are determined.

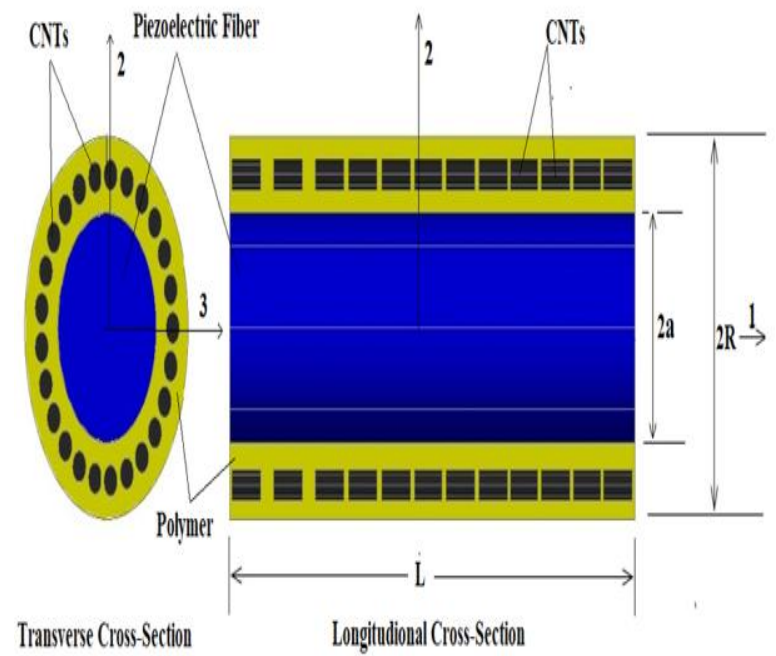

Fig.2 Cross sections of PNPC

The constructional feature of hybrid smart composites is that the piezoelectric (PZT) material are used as vertically cylindrical fibers and CNTs are uniformly aligned along the circumferential surface of PZT in the direction of PZT and polyimide is used as matrix.

\section{GOVERNING MORI TANAKA EQUATIONS}

The novel work of Mori-Tanaka method (MTM) has been effectively employed in the analysis of composites [17]. Mori-Tanaka proposed a rationalized method to find out the relation between average strains and average stresses for composites. MTM was reformulated by Benveniste [8] for the determination of effective coefficients of composites with different shape and size of inclusions.

The procedure for MTM for multiple inclusions [18] can be derived for prediction of the effective coefficients of twophase composite by solving the following equations:-

$$
[\mathrm{C}]=\left[\mathrm{C}_{1}\right]+\mathrm{v}_{2}\left(\left[\mathrm{C}_{2}\right]-\left[\mathrm{C}_{1}\right]\right)\left[\mathrm{F}_{\mathrm{a}}\right]
$$$$
\{\mathrm{e}\}=\mathrm{v}_{\mathrm{f}}\left[\mathrm{F}_{\mathrm{a}}\right]\left\{\mathrm{e}_{1}\right\}
$$

Where

$\left[\mathrm{F}_{\mathrm{a}}\right]=\left[\mathrm{F}_{\mathrm{b}}\right] /\left(\mathrm{v}_{1}+\mathrm{v}_{2}\left[\mathrm{~F}_{\mathrm{b}}\right]\right)$,

$\left[\mathrm{F}_{\mathrm{b}}\right]=\left[\mathrm{C}_{1}\right] /\left(\left[\mathrm{C}_{1}\right]+[\mathrm{S}]\left(\left[\mathrm{C}_{2}\right]-\left[\mathrm{C}_{1}\right]\right)\right)$ and $\quad\left\{\mathrm{e}_{1}\right\}=$ $\left\{\begin{array}{c}\mathrm{e}_{11} * \mathrm{v}_{2} \\ \mathrm{e}_{12} \\ \mathrm{e}_{13} \\ 0 \\ 0 \\ 0\end{array}\right\}$

In equations (1) and (2), the strain concentration factors are $\left[\mathrm{F}_{\mathrm{a}}\right]$ and $\left[\mathrm{F}_{\mathrm{b}}\right]$, elastic constant matrix of the composite is $[C],\{\mathrm{e}\}$ is the piezoelectric constant matrix of the composite, $\mathrm{v}_{\mathrm{f}}$ represents volume fraction of the piezoelectric and $[\mathrm{S}]$ represents Eshelby tensor matrix. The volume fractions for matrix and CNT fiber are $v_{1}$ and $v_{2}$ respectively. Elastic constant matrices for matrix and fiber are $\left[\mathrm{C}_{1}\right]$ and $\left[\mathrm{C}_{2}\right]$ respectively.

Inclusion problems can be solved with the help of Eshelby tensor [12] in the MTM approach. This tensor is valuable in finding out various aspects of composites. The Eshelby tensor is shown in equation (3).

$$
[S]=\left[\begin{array}{cccccc}
\mathrm{S}_{11} & \mathrm{~S}_{12} & \mathrm{~S}_{13} & 0 & 0 & 0 \\
\mathrm{~S}_{21} & \mathrm{~S}_{22} & \mathrm{~S}_{23} & 0 & 0 & 0 \\
\mathrm{~S}_{31} & \mathrm{~S}_{32} & \mathrm{~S}_{33} & 0 & 0 & 0 \\
0 & 0 & 0 & 2 \mathrm{~S}_{44} & 0 & 0 \\
0 & 0 & 0 & 0 & 2 \mathrm{~S}_{55} & 0 \\
0 & 0 & 0 & 0 & 0 & 2 \mathrm{~S}_{66}
\end{array}\right]
$$

Where,

$$
\begin{gathered}
\mathrm{S}_{11}=0, \mathrm{~S}_{12}=0, \quad \mathrm{~S}_{13}=0 \mathrm{~S}_{21}=\frac{1}{2(1-v)}\left(\frac{2 v \mathrm{a}_{3}}{\mathrm{a}_{2}+\mathrm{a}_{3}}\right), \\
\mathrm{S}_{22}=\frac{1}{2(1-v)}\left\{\frac{\mathrm{a}_{3}^{2}+2 \mathrm{a}_{2} \mathrm{a}_{3}}{\left(\mathrm{a}_{2}+\mathrm{a}_{3}\right)^{2}}+\frac{(1-2 v) \mathrm{a}_{3}}{\left(\mathrm{a}_{2}+\mathrm{a}_{3}\right)}\right\}, \\
\mathrm{S}_{23}=\frac{1}{2(1-v)}\left\{\frac{\mathrm{a}_{3}^{2}}{\left(\mathrm{a}_{2}+\mathrm{a}_{3}\right)^{2}}-\frac{(1-2 v) \mathrm{a}_{3}}{\left(\mathrm{a}_{2}+\mathrm{a}_{3}\right)}\right\}, \mathrm{S}_{31}=\frac{1}{2(1-v)}\left(\frac{2 v \mathrm{a}_{2}}{\mathrm{a}_{2}+\mathrm{a}_{3}}\right), \\
\mathrm{S}_{32}=\frac{1}{2(1-v)}\left\{\frac{\mathrm{a}_{2}^{2}}{\left(\mathrm{a}_{2}+\mathrm{a}_{3}\right)^{2}}-\frac{(1-2 v) \mathrm{a}_{2}}{\left(\mathrm{a}_{2}+\mathrm{a}_{3}\right)}\right\}, \\
\mathrm{S}_{33}=\frac{1}{2(1-v)}\left\{\frac{\mathrm{a}_{2}^{2}+2 \mathrm{a}_{2} \mathrm{a}_{3}}{\left(\mathrm{a}_{2}+\mathrm{a}_{3}\right)^{2}}+\frac{(1-2 v) \mathrm{a}_{2}}{\left(\mathrm{a}_{2}+\mathrm{a}_{3}\right)}\right\}, \\
\text { and }_{66}=\frac{\mathrm{a}_{3}}{2\left(\mathrm{a}_{2}+\mathrm{a}_{3}\right)}
\end{gathered}
$$

Where $v=$ Poisson ratio, $\mathrm{a}_{2}=$ Major axis of ellipse and $\mathrm{a}_{3}=$ Minor axis of ellipse 
Eshelby tensor is dependent on the properties of matrix material and the shape of the fiber. The calculation of the effective coefficients is carried out by Eshelby tensor [S] for elliptical cylinder inclusion and shown in equation (3).

\section{VALIDATION OF METHOD}

The results obtained for the proposed composite by MTM method are compared for the composite given by [9].

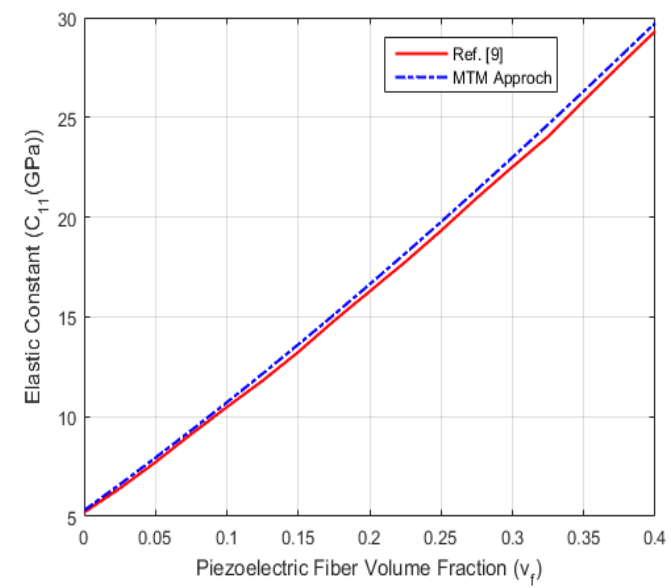

Fig.3 Validation of effective elastic properties $\mathbf{C}_{11}$

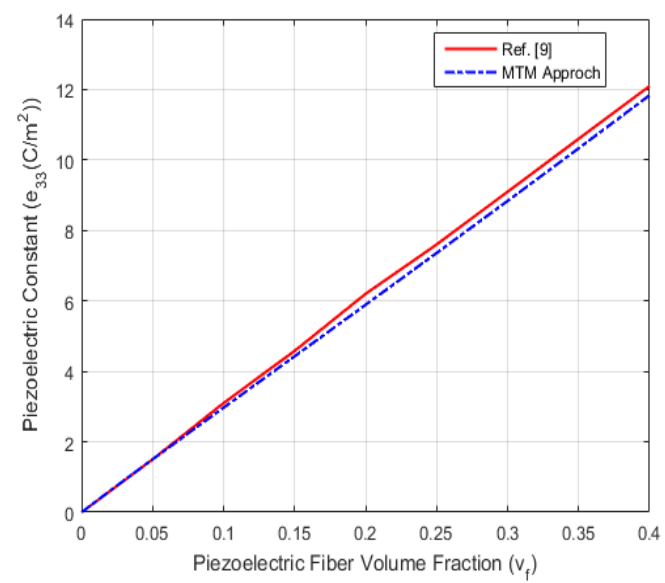

Fig.4 Validation of effective piezoelectric of the composite ${ }_{33}$ of the composite

These results for effective elastic constants and effective piezoelectric constants are plotted with the piezoelectric fiber volume fractions, which are shown in Fig. 3 and Fig.4. These figures shows the fine conformity with the results of [9] for the same composite material. Therefore the proposed method can be used for further prediction of properties of composites for different models.

\section{EFFECTIVE PROPERTIES OF COMPOSITE}

The effective properties are calculated for three different types of CNTs. The various different types of CNTs are used for comparison purpose. For this purpose CNT $(10,0)$, $(14,0)$ and $(18,0)$ are used.

In the first step, CNTs are used as fibers and polyimide as a matrix, the resulting composite is known as nano composite (NC). In the second step Piezoelectric material is used as fibers and NC is used as matrix, the resulting composite is known as piezoelectric nano composite (PNC). In the third step, PNC is used as fibers and Polyimide as a matrix, the resulting composite is known as piezoelectric nano polyimide composite (PNPC).

The properties of this nanocomposite are estimated by employing MTM technique. For this purpose, equations (1) and (2) are solved.

\section{RESULTS AND DISCUSSION}

The mathematical results found from MTM approach are plotted in this section. Effective elastic and piezoelectric constants are determined by MTM approach. Table 1 shows the material properties of CNTs, PZT and polyimide matrix $[4,10]$. Effective properties of the proposed PNPC composite are obtained by varying volume fractions of fibers and matrix.

Table 1 Material properties of the different phase materials $[4,10]$.

\begin{tabular}{|c|c|c|c|c|c|c|c|c|}
\hline $\begin{array}{l}\text { Materia } \\
1\end{array}$ & $\begin{array}{l}\mathrm{C}_{11} \\
(\mathrm{G} \\
\mathrm{Pa})\end{array}$ & $\begin{array}{l}\mathrm{C}_{12} \\
\text { (GP } \\
\text { a) }\end{array}$ & $\begin{array}{l}\mathrm{C}_{23} \\
\text { (GP } \\
\text { a) }\end{array}$ & $\begin{array}{l}\mathrm{C}_{33} \\
\text { (GP } \\
\text { a) }\end{array}$ & $\begin{array}{l}\mathrm{C}_{55} \\
\text { (GP } \\
\text { a) }\end{array}$ & $\begin{array}{l}\mathrm{d} \\
(\mathrm{nm})\end{array}$ & $\begin{array}{l}\mathrm{e}_{31} \\
(\mathrm{C} / \\
\mathrm{m}^{2} \\
)\end{array}$ & $\begin{array}{l}\mathrm{e}_{33} \\
(\mathrm{C} / \\
\left.\mathrm{m}^{2}\right)\end{array}$ \\
\hline $\begin{array}{l}\text { CNT } \\
(10,0)\end{array}$ & $\begin{array}{l}70 \\
9.9\end{array}$ & $\begin{array}{l}172 . \\
4\end{array}$ & 240 & $\begin{array}{l}151 \\
3.1\end{array}$ & $\begin{array}{l}112 \\
0\end{array}$ & 0.78 & & \\
\hline $\begin{array}{l}\text { CNT } \\
(14,0)\end{array}$ & $\begin{array}{l}55 \\
7.5\end{array}$ & $\begin{array}{l}137 . \\
5\end{array}$ & $\begin{array}{l}187 \\
.7\end{array}$ & $\begin{array}{l}108 \\
2.8\end{array}$ & $\begin{array}{l}779 \\
.2\end{array}$ & 1.1 & & \\
\hline $\begin{array}{l}\text { CNT } \\
(18,0)\end{array}$ & $\begin{array}{l}47 \\
2.9\end{array}$ & $\begin{array}{l}118 . \\
7\end{array}$ & $\begin{array}{l}159 \\
.7\end{array}$ & $\begin{array}{l}846 . \\
1\end{array}$ & $\begin{array}{l}569 \\
.3\end{array}$ & 1.42 & & \\
\hline PZT 5H & $\begin{array}{l}15 \\
1\end{array}$ & 98 & 96 & 124 & 23 & $\begin{array}{l}100 \\
00\end{array}$ & $\begin{array}{l}- \\
5.1\end{array}$ & 27 \\
\hline $\begin{array}{l}\text { Polyimi } \\
\text { de }\end{array}$ & 9 & 6 & 6 & 9 & 1.5 & - & & \\
\hline
\end{tabular}

Three types of CNTs are used for plotting the results and CNT length is taken as $1.63 \mathrm{~nm}$. The volume fraction of nanotubes in PNPC relies on the diameter of nanotubes, piezoelectric fiber (PZT) volume fraction and the surface distance between two nanotubes. The gaps between the CNTs are filled by the polyimide matrix.

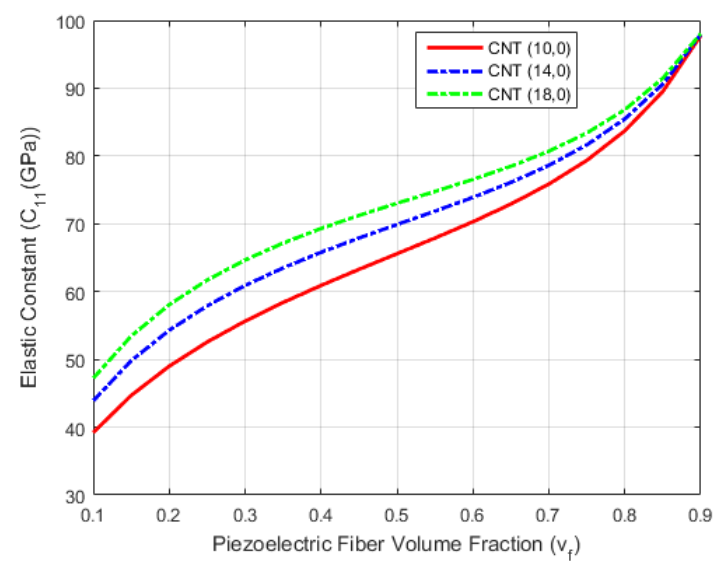

Fig.5 Effective elastic properties $\mathrm{C}_{11}$ of thePNPC composite

Published By: 


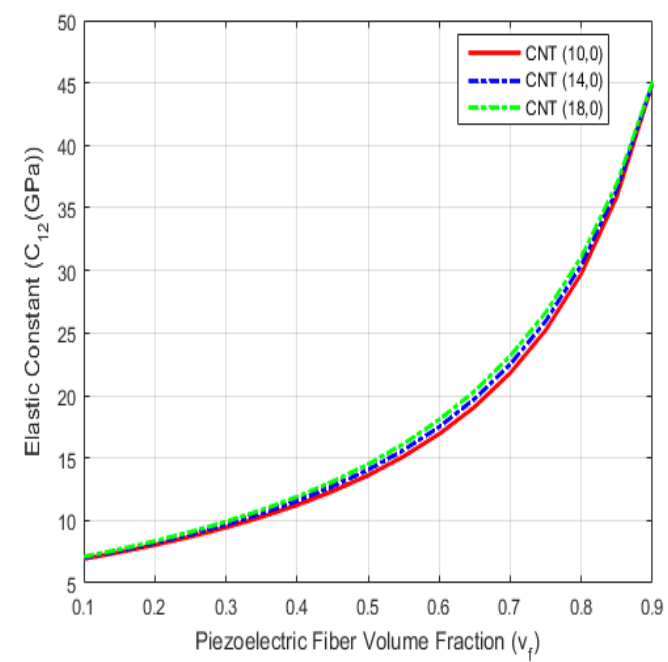

Fig.6 Effective elastic properties $\mathrm{C}_{12}$ of the PNPC composite

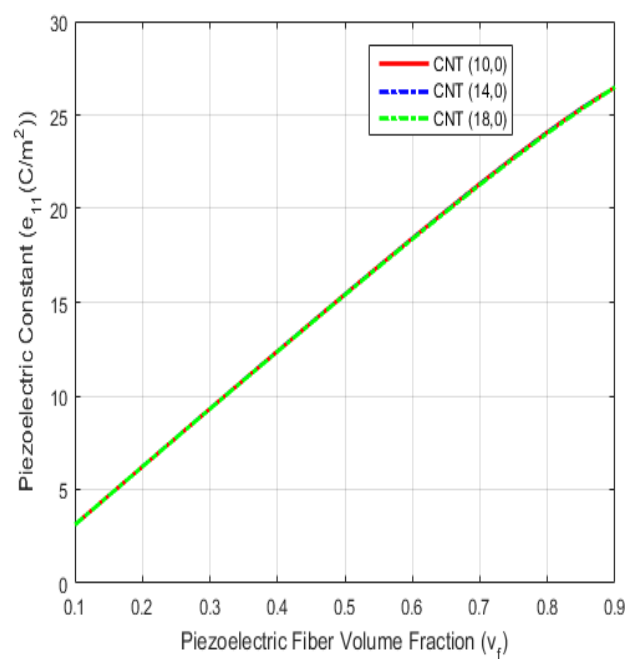

Fig.7 Effective piezoelectric properties $\mathrm{e}_{11}$ of the PNPC composite

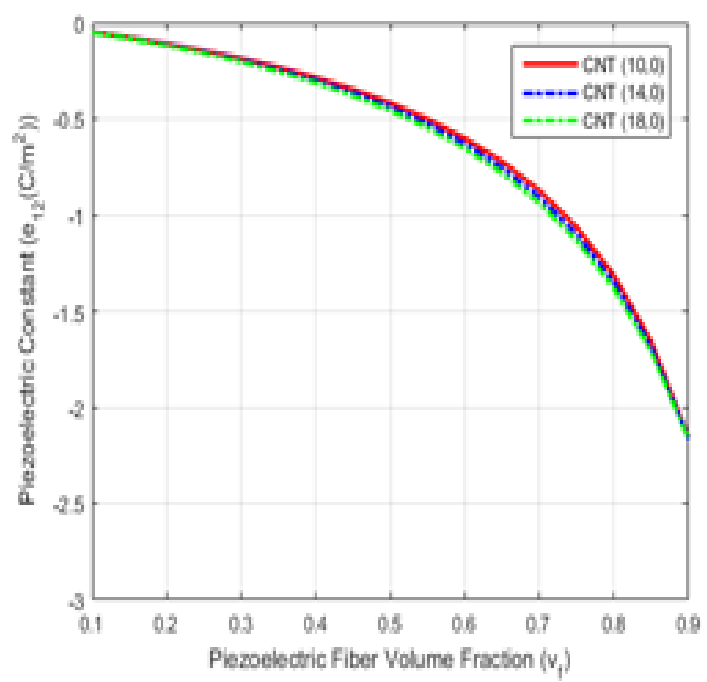

Fig.8 Effective piezoelectric properties $\mathrm{e}_{12}$ of the PNPC composite

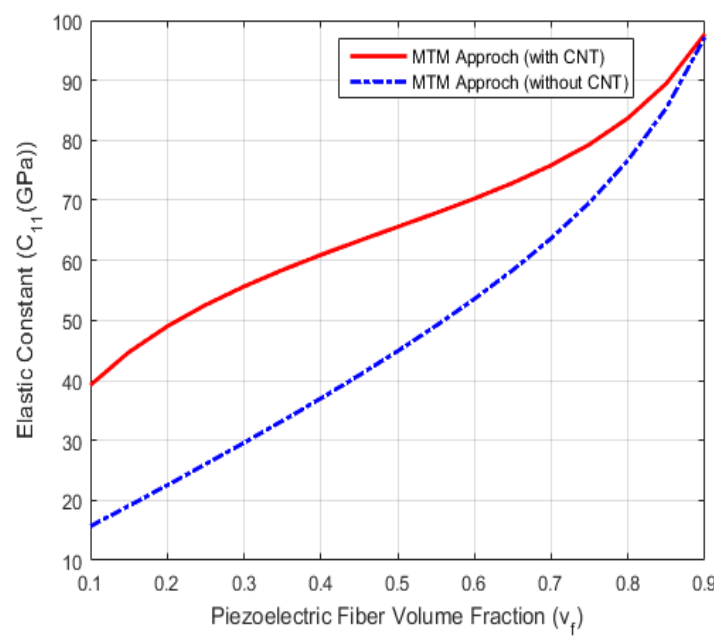

Fig.9 Effective elastic properties $\mathrm{C}_{11}$ of the PNPC compositewith or without $\mathrm{CNTs}$

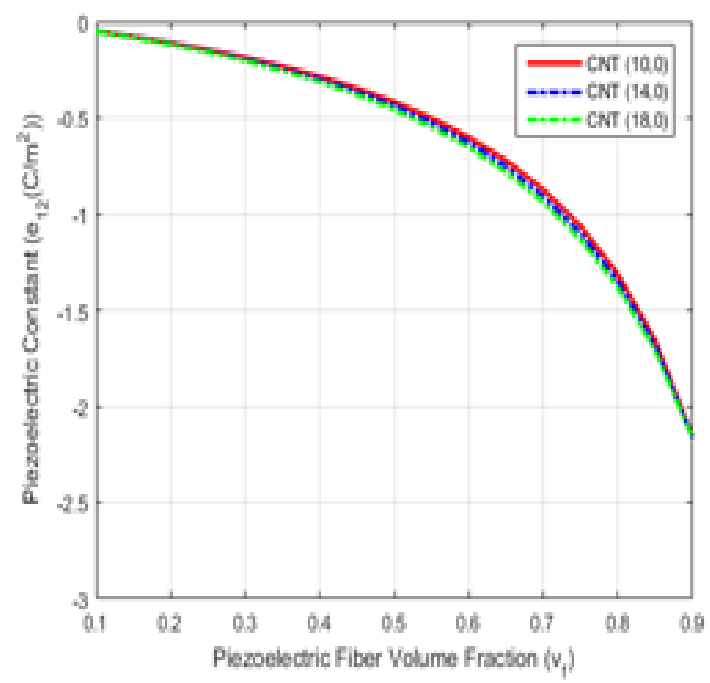

Fig.10 Effective elastic properties $\mathrm{C}_{23}$ of PNPC composite with or without $\mathrm{CNTs}$

Fig.5 to Fig.10 shows the variation of effective elastic and piezoelectric constants with the piezoelectric fiber volume fraction for three different diameters of CNTs. Fig.5 shows the variation of longitudinal elastic coefficients and it is depicted from this figure, the longitudinal elastic coefficients of CNTs increases with the increase in diameter of CNTs. It means CNT $(18,0)$ have more value of longitudinal constants than the CNT $(10,0)$.

Fig. 6 shows the variation of transverse elastic constants with piezoelectric fiber volume fraction. The transverse properties are slightly improved with the increase in diameter of CNTs. Variation of effective piezoelectric coefficients with piezoelectric fiber volume fraction is shown in Fig.7 and Fig.8. It can be depicted from these Fig.7 and Fig.8, that there is almost no change in piezoelectric coefficients with the change in diameter of CNTs. 
Fig.9 and Fig.10 show the variation of longitudinal and transverse elastic constants with piezoelectric fiber volume fraction. The comparison between with and without using CNTs are done in these plots. It can be noted from these figures that, there is a significant enhancement in longitudinal elastic constants with the addition of CNT. Also, there is slight improvement in transverse properties with the addition of CNTs.

\section{CONCLUSION}

In this paper, a new hybrid smart nano composite model was proposed and effective properties were determined for three different diameters of CNTs. The MTM approach was used for the analysis purpose.The results show that there is a significant enhancement in longitudinal properties and slightly increment in transverse properties when CNTs are used. The different diameters of CNTs were taken for the analysis purpose. The effect of CNT diameters on the volume fractions of piezoelectric fibers for the proposed composite is examined. It is found that the change in diameter can play a crucial role in the determination of effective properties of CNT reinforced hybrid composites.

The proposed PNPC will have superior quality against the delamination failure of composites. Because of the increase in the value of longitudinal properties, the proposed hybrid reinforced smart composite can act as a distributed actuator for both in-plane and out-of-plane actuation.

\section{REFERENCES}

1. S. Iijima. Helical microtubules of graphitic carbon. Nature 1991, Vol. 354: PP. 56-58.

2. Odegard G. M. et al, Mechanical properties of Graphene Nano platelet/Epoxy Composites, Journal of applied polymer science, 2013, APP. 38645: PP. 4217-4223

3. Kaushik B. K. and Majumdar M. K., Carbon Nanotube Based VLSI Interconnects, Analysis and Design, Springer Briefs in Applied Sciences and Technology, 2015, ISBN No 978-81-322-2046-6 chapter 2, PP. 17-22.

4. Ray M. C. and Batra R. C. Effective properties of CNT and piezoelectric fiber reinforced hybrid smart composites. ASME Journal of Applied Mechanics, 2009, Vol. 76 /PP. 0345031-4.

5. Mori T. and Tanaka K. Average stress in matrix and average elastic energy of materials without misfitting inclusions. Acta Metallurgica, 1973, Vol. 21, PP. 571574.

6. Liu L. and Huang Z. A Note on Mori-Tanaka's method. Acta Mechanica Solida Sinica, 2014, Vol. 27, No. 3. PP. 234-244.

7. Bohayra Mortazavi et al, Modeling of two-phase random composite materials by finite element, Mori-Tanaka and strong contrast methods, Composites: Part B 45 (2013) $1117-1125$.

8. Benveniste $\mathrm{Y}$. On the micromechanics of fibrous piezoelectric composites. Mechanics of materials, 1994, Vol. 18, PP. 183-193.

9. Ray M. C. The concept of novel hybrid smart composite reinforced with radially aligned zigzag carbon nanotubes on piezoelectric fibers". Smart Mater. Struct, 2010, Vol. 19, 035008 (8 pp).

10. Kundalwal S. I. and Ray M. C. Micromechanical analysis of fuzzy fiber reinforced composites. Int J. Mech Mater Des, 2011, Vol. 7, PP. 149-166.

11. Eshelby J. D., The determination of the elastic field of an ellipsoidal inclusion, and related problems, Proceedings of the Royal Society of London. Series A, Mathematical and Physical Sciences, 1957, PP. 376-396.

12. Huang J. et al. Magneto-electro-elastic Eshelby tensors for a piezoelectric-piezomagnetic composite reinforced by ellipsoidal inclusions. Journal of Applied Physics, 1998, Vol. 83, No. 10: PP. 5364-70.

13. Shinji Muraishi Minoru and Taya, Average Eshelby tensor and elastic field for helical inclusion problems, International Journal of Solids and Structures 180-181 (2019) PP. 125-136.

14. Barnett D. M. and Cai Wei, Properties of the Eshelby tensor and existence of the equivalent ellipsoidal inclusion solution, Journal of the Mechanics and Physics of Solids 121 (2018) PP. 71-80.

15. Dinzart F. and Sabar H., Electroelastic ellipsoidal inclusion with imperfect interface and its application to piezoelectric composites, International Journal of Solids and Structures 136-137 (2018) PP. 241-249.

16. Shen $\mathrm{Li}$ and $\mathrm{Li}$ Jack. Transversely isotropic elastic properties of single walled carbon nanotubes. Physical Review, 2004, Vol. B69, PP. 045414-1-10.

17. Mori T. and Tanaka K. Average stress in matrix and average elastic energy of materials without misfitting inclusions. Acta Metallurgica, 1973, Vol. 21, PP. 571574

18. Dunn M. L. and Ledbetter H. Elastic moduli of composites reinforced by multiphase particles. Journal of Applied Mechanics, 1995, Vol. 62, PP. 1023-28.

\section{REFERENCES}

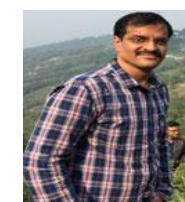

Mr S. S. Godara is a research scholar in the Department of Mechanical Engineering at Indian Institute of Technology (Indian School of Mines), Dhanbad, India. He received B.Tech. in Mechanical Engineering, from Govt Engineerng College Ajmer and after that he did his M.Tech. from Indian Institute of Technology Kharagpur. His research interests include composite materials, design, finite element analysis etc.

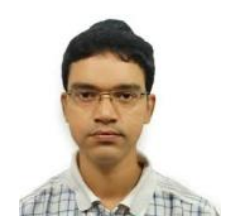

Dr. P. K. Mahato is an associate professor in the Department of Mechanical Engineering at Indian Institute of Technology (Indian School of Mines), Dhanbad, India. He obtained his doctorate (Ph.D.) from Indian Institute of Technology Kharagpur. His research interests in Composite Materials, Active Vibration Control, Computational Mechanics, Aeroelasticity etc. 